\section{PENENTUAN KRITERIA CACAT KULIT UNTUK TIGKAT KUALITAS KULIT}

\section{SULIESTIYAH. Wrd *)}

\section{ABSTRACT}

The aim of this study was to present data for preparing quality standard of sun dry sheep skins. Samples used for this study were 70 sides of sun dry sheep skins in various quality ranging from first to rejected onegraded by skin colectors and tanners in Java, which were radomli taken. Visually, they were classified into several classes by the team in accordance with qualitative value of theoritical studies carried-out bay LRI (1962) and Aten et al (1955). The results of both classification then were compared to each other. A enclusion was drawn from this study that results of on sun dry sheep skins quality on basis of defect criteria could not be used as data in preparing quality standard of skins (for subyective factors were very much influenced). Table of evalution on skins quality prepared by the team could be used as a guide in quantitative grading. It was stated from visual inspection of sheep skins qualitatively that : avarage value of quality $I=95$, quality $I I=84,29$, quality $\mathrm{III}=68,76$ and quality $\mathrm{IV} / \mathrm{AF}=40,92$.

*) Kasi Tekno Ekonomi, Balai Pengembangan Barang Kulit.

\section{INTISARI}

Tujuan penelitian ini adalah menyajikan data untuk bahan penyusunan standar mutu kulit mentah kambing yang diawet dengan sinar matahari. Dengan menggunakan sampel 70 lembar kulit kambing (PE) mentah yang diawet dengan sinar matahari, yang diambil secara random dari para pengumpul/pedagang kulit dan penyamak kulit yang tersebar di seluruh Jawa. Sampel tersebut diambil dari bermacam-macam kulit yang ada dari kualitas I sampai dengan reject, berdasarkan penilaian kualitas masing-masing dari para pedagang/pengumpul kulit serta penyamak kulit. Dengan cara organoleptis kulit-kulit tersebut diklasifikasikan menjadi beberapa kelas (oleh team) berdasarkan penilaian kualitatip dari teori-teori yang pernah dikemukakan oleh BPK (1962) dan Aten et al (1955). Hasil klafikasi dari pedagang/ pengumpul kulit serta penyamak kulit kemudian dibandingkan dengan hasil klasifikasi oleh team. Dari hasil penelitian dapat disimpulkan bahwa penilaian kualitas kulit mentah kambing yang diawet dengan sinar matahari secara organoleptis berdasarkan kriteria cacat-cacat yang ada pada kulit, tidak dapat dijadikan dasar untuk menyusun standar mutu kulit mentah (karena sangat dipergunakan oleh faktor subyectivitas.) Tabel Penilaian kualitas kulit mentah yang telah disusun oleh team dapat dijadikan pedoman dalam grading kulit mentah secara kuantitatip. Dalam penilaian kualitas kulit secara kualitatip berdasarkan organoleptis menghasilkan : nilai rata-rata kualitas $I=95$, kualitas $\mathrm{II}=84,29$, kualitas $\mathrm{III}=68,76$, dan kualitas $\mathrm{IV} / \mathrm{AF}=40$, 92.

\section{PENDAHULUAN}

Kulit mentah merupakan bahan baku utama bagi industri perkulitan. Disamping pengadaan bahan baku, maka mutu bahan baku itu sendiri sangat besar pengaruhnya terhadap perkembangan industri perkulitan.

Menurut Herwijnen (1956), bahwa menentukan kualitas kulit mentah perlu dilihat struktur adanya cacat pada kulit, perbandingan tebal yang bagus pada krupon, leher dan bahu. Baik buruknya struktur kulit mentah oleh Wikantadi (1969) ; BPK (1962) dan Herwijnen (1956), dikatakan bahwa kulit awetan yang baik harus memenuhi syarat sebagai berikut : kulit bulunya kelihatan hidup dan tidak suram, tidak ada bulu yang rontok karena bakteri pembusuk, tidak ada flek putih kekuning-kuningan, serta kulit tidak berbau. Menurut BPK (1962), cacat pada kulit mentah dapat disebabkan oleh : cacat yang ditimbulkan sewaktu dalam pengerjaan pengulitan. Cacat yang ditimbulkan sewaktu hewan masih hidup, dapat disebabkan dari : Scabies, cacar atau pocken, pest dan bekas gesekan atau kena pukul. Dikatakan oleh Hernowo (1972), kesalahan-kesalahan yang terjadi pada proses pengulitan pada kambing tidaklah menjadi masalah yang serius, hal ini berbeda dengan sapi dimana tidak terampilnya pengkulit akan mengakibatkan kerusakankerusakan yang akan sangat menurunkan kualitas kulit.

Untuk menentukan banyak sedikitnya cacat pada kulit mentah, maka BPK telah mengadakan penelitian tentang penentuan kualitas kulit mentah kering dengan menggunakan alat elektronik.

Dari hasil penelitian dapat diambil kesimpulan bahwa kualitas kulit mentah yang telah disortir secara organoleptis tidak sama hasilnya dalam menen tukan kualitas mentah dengan menggunakan alat elektronik disebabkan adanya faktor yang mempengaruhi (gudik, bulu, kotoran/debu, goresan pisau, tebal/tipis kulit, dsb.)

Oleh karena penentuan kualitas kulit dengan menggunakan alat elektronik sulit diterapkan, maka penelitian ini akan dicoba secara organoleptis terhadap kualitas kulit mentah kambing yang diawet dengan sinar matahari. Hasil penelitian diharapkan dapat dijadikan pedoman secara kuantitatip untuk grading kulit mentah bagi para pengumpul/pedagang kulit mentah.

Tujuan penelitian adalah untuk menentukan kriteria cacat-cacat yang terdapat pada kulit mentah kambing yang diawet dengan sinar matahari serta menyajikan data-data kuantitatip guna menyusun standar mutu kulit mentah kambing yang diawet dengan sinar matahari. 


\section{MATERI DAN METODE}

Materi penelitian terdiri dari 70 lembar kulit mentah kambing (PE), yang diawet dengan sinar matahari. Sampel diambil secara random dari pedagang/ pengumpul kulit serta penyamak kulit yang berada di Pulau Jawa. Kulit diambil dari bermacam-macam kualitas kulit yang ada, berdasarkan penilaian dari para pedagang/pengumpul kulit, serta penyamak kulit. Daerah pengambilan sampel meliputi : Jawa Timur 30 sampel, Jawa Tengah 20 sampel DKI-Jaya 15 sampel, Jawa Barat 15 sampel.

Sampel diambil secara random dari pedagang/pengumpul kulit serta penyamak kulit yang berada di Pulau Jawa. Kulit diambil dari para pedagang/ pengumpul kulit, serta penyamak kulit. Daerah pengambilan sampel meliputi : Jawa Timur 30 sampel, Jawa Tengah 20 sampel, DKI-jaya 15 sampel, lawa Barta 15 sampel.

Sampel kemudian dinilai oleh team yang ada di BBKKP (sudah biasa nenilai mutu kulit mentah), berdasarkan faktor defects yang mempunyai niai maksimum 100 (untuk kulit yang tidak mempunyai cacat). Penilaian cualitas kulit berdasarkan teori yang sudah ada di Balai Penelitian Kulit 1962) dan Aten et al (1955).

Dari hasil pengamatan seluruh sampel kemudian dianalisa secara statisik berdasar score ranking. Rata-rata score rangking dicari dengan non paranetric method, atas dasar score rangking table yang telah ditetapkan krierianya oleh Kramer dan Twigg sebagai berikut :

\section{Tabel 1 : Score ranking}

\begin{tabular}{|ll|r|}
\hline Kriteria & Score ranking \\
\hline Sempurna & (excellent) & $100-80$ \\
Baik & (good) & $79-60$ \\
Cukup & (fair) & $59-40$ \\
Jelek & (poor) & $39-20$ \\
Sangat jelek (very poor) & $19-0$ \\
\hline
\end{tabular}

Kualitas kulit dinilai secara organoleptik, berdasarkan prosentase jumlah acat dan macam cacat yang terdapat pada kulit. Bentuk kulit serta sisa daing dan lemak, merupakan faktor yang diperhatikan pula dalam menilai ualitas kulit. Nilai maksimum untuk kulit yang tidak ada cacatnya diberi nii 100. Penilaian cacat dibedakan daerah : krupon, leher, perut, kaki dan kor. Perbedaan nilai tersebut berdasarkan berapa luas kulit dan kegunaan lasing-masing bagian secara ekonomis. Dari cara penilaian tersebut mengasilkan tabel sebagai berikut :
Tabel 2: Penilaian Kualitas Kulit

\begin{tabular}{|c|c|c|c|c|c|c|}
\hline No & Faktor/Bagian Kulit & $\begin{array}{l}\text { Kru- } \\
\text { pon } \\
(60)\end{array}$ & $\begin{array}{c}\text { Leher } \\
\text { (10) }\end{array}$ & $\begin{array}{c}\text { Perut } \\
\text { (25) }\end{array}$ & $\begin{array}{c}\text { Kaki }+ \\
\text { Ekor } \\
(5)\end{array}$ & \begin{tabular}{|c} 
Jumlah \\
Nilai \\
$(100)$
\end{tabular} \\
\hline 2. & $\begin{array}{l}\text { Flaying Defects } \\
\text { a. Macam + banyaknya } \\
\text { cacat }(75 \%) \\
\text { b. Bentuk kulit } \\
(10 \%) \\
\text { c. Sisa daging + lemak } \\
(15 \%) \\
\text { Cacat penyakit } \\
\text { a. Gudig }(30 \%) \\
\text { b. Pest }(65 \%) \\
\text { c. lain-lain }(5 \%)\end{array}$ & & & & and & \\
\hline
\end{tabular}

Penilaian kualitas kulit, berdasrkan kepada 2 macam faktor cacat kuli yang sangat mempengaruhi terhadap kualitas dari kulit yaitu :

- Cacat yang disebabkan oleh akibat pengulitan (flaying defect)

- Cacat yang disebabkan oleh akibat adanya penyakit.

Setelah kulit dinilai dengan tabel penilaian kualitas kulit, kemudian hasilnya dibandingkan dengan tabel penilaian kualitas kulit menurut para pedagang pengumpul kulit dan penyamak kulit.

\section{HASIL PENELITIAN}

Penilaian kualitas kulit mentah kambing kering secara organoleptis dengan cara : kulit direntang dengan tangan, kemudian dilihat dibawah sinar matahari atau di tempat terang. Karena kulit kambing tipis dan agak transparan maka cacat-cacat yang terdapat pada kulit (cacat mekanis dan cacat karena penyakit) dapat dilihat dengan jelas. Struktur dan letak cacat kulit diperhatikan, juga tebal/tipis kulit akan berpengaruh terhadap kualitas kulit. Hasil penelitian dalam menentukan kualitas kulit, berdasarkan cacat yang ada pada kulit, dapat dilihat pada tabel berikut: 
Tabel 3 : Hasil penilaian kualitas kulit di Jawa Timur (Secara kuantitatip oleh team BBKKP)

\begin{tabular}{|c|c|c|c|c|c|}
\hline No & $\begin{array}{c}\text { Krupon } \\
(60)\end{array}$ & $\begin{array}{c}\text { Leher } \\
(10)\end{array}$ & $\begin{array}{l}\text { Perut } \\
\text { (25) }\end{array}$ & $\begin{array}{c}\text { Kaki+Ekor } \\
(5) \\
\end{array}$ & $\begin{array}{c}\text { Jumlah } \\
\text { Nilai }\end{array}$ \\
\hline 1. & 49,05 & 7,92 & 20,03 & 4,01 & 81,01 \\
\hline 2. & 56,62 & 9,74 & 20,41 & 4,88 & 91,65 \\
\hline 3. & 34,01 & 5,39 & 13,47 & 2,79 & 55,66 \\
\hline 4. & 54,94 & 9,23 & 22,00 & 4,53 & 90,70 \\
\hline 5. & 51,55 & 8,61 & 19,56 & 4,01 & 83,73 \\
\hline 6. & 59,77 & 9,72 & 25,00 & 4,98 & 99,47 \\
\hline 7. & 53,02 & 8,78 & 23,59 & 4,56 & 89,95 \\
\hline 8. & 55,65 & 9,27 & 24,41 & 4,60 & 93,93 \\
\hline 9. & 17,25 & 2,78 & 7,19 & 1,42 & 28,64 \\
\hline 10. & 56,17 & 8,82 & 23,26 & 5,00 & 93,25 \\
\hline 11. & 60,00 & 9,91 & 25,00 & 4,99 & 99,90 \\
\hline 12. & 45,49 & 8,78 & 21,72 & 4,30 & 80,29 \\
\hline 13. & 29,40 & 4,30 & 9,34 & 2,10 & 45,14 \\
\hline 14. & 37,84 & 7,24 & 19,84 & 4,15 & 69,07 \\
\hline 15. & 45,71 & 7,97 & 19,70 & 4,00 & 77,38 \\
\hline 16. & 25,35 & 7,82 & 18,39 & 1,70 & 53,26 \\
\hline 17. & 16,46 & 2,72 & 6,72 & 1,34 & 27,24 \\
\hline 18. & 23,44 & 5,22 & 12,81 & 3,22 & 44,69 \\
\hline 19. & 45,15 & 6,91 & 17,26 & 3,22 & 72,54 \\
\hline 20. & 32,89 & 7,45 & 18,25 & 3,72 & 62,31 \\
\hline
\end{tabular}

Tabel 4 : Hasil penelitian kualitas kulit di Jawa Tengah Secara kuantitatip oleh Team BBKKP

\begin{tabular}{|r|c|r|r|r|c|}
\hline No & $\begin{array}{c}\text { Krupon } \\
(60)\end{array}$ & $\begin{array}{c}\text { Leher } \\
(10)\end{array}$ & $\begin{array}{c}\text { Perut } \\
(25)\end{array}$ & $\begin{array}{r}\text { Kaki+Ekor } \\
(5)\end{array}$ & $\begin{array}{c}\text { Jumlah } \\
\text { Nilai }\end{array}$ \\
\hline 1. & 51,45 & 10,45 & 21,96 & 4,39 & 88,25 \\
2. & 23,77 & 3,95 & 10,42 & 2,74 & 40,88 \\
3. & 39,07 & 6,86 & 18,62 & 3,71 & 68,26 \\
4. & 24,22 & 4,02 & 12,52 & 1,76 & 42,52 \\
5. & 47,17 & 7,80 & 11,28 & 4,24 & 70,49 \\
6. & 20,62 & 3,31 & 8,73 & 1,74 & 34,40 \\
7. & 37,27 & 6,19 & 15,52 & 3,10 & 62,08 \\
8. & 24,45 & 5,07 & 11,41 & 2,10 & 42,94 \\
9. & 19,94 & 3,33 & 8,87 & 2,34 & 34,48 \\
10. & 27,37 & 8,79 & 18,53 & 3,70 & 58,39 \\
11. & 33,67 & 10,36 & 23,17 & 4,62 & 71,53 \\
12. & 37,04 & 8,11 & 11,94 & 3,81 & 60,90 \\
13. & 24,89 & 7,40 & 23,12 & 4,62 & 60,03 \\
14. & 39,64 & 8,41 & 20,41 & 4,08 & 72,54 \\
15. & 36,48 & 5,05 & 20,03 & 2,19 & 63,75 \\
16. & 31,14 & 7,20 & 13,84 & 2,69 & 54,87 \\
17. & 36,31 & 4,18 & 20,97 & 4,09 & 65,55 \\
18. & 17,79 & 3,32 & 4,20 & 1,41 & 26,72 \\
19. & 27,14 & 8,90 & 22,64 & 4,54 & 63,22 \\
20. & 47,17 & 7,80 & 11,28 & 4,24 & 70,49 \\
\hline
\end{tabular}


Tabel 5 : Hasil Penilaian kualitas kulit di Jawa Barat Secara kuantitatip oleh Team BBKP

\begin{tabular}{|c|c|c|c|c|c|}
\hline No & $\begin{array}{c}\text { Krupon } \\
(60)\end{array}$ & $\begin{array}{c}\text { Leher } \\
(10)\end{array}$ & $\begin{array}{c}\text { Perut } \\
(25)\end{array}$ & $\begin{array}{c}\text { Kaki+Ekor } \\
(5)\end{array}$ & $\begin{array}{c}\text { Jumlah } \\
\text { Nilai }\end{array}$ \\
\hline 1. & 60,00 & 10.00 & 25,00 & 5,00 & 100,00 \\
2. & 17,25 & 0,81 & 8,87 & 2,02 & 28,95 \\
3. & 56,74 & 10,07 & 23,00 & 4,47 & 94,36 \\
4. & 41,32 & 8,86 & 23,60 & 4,68 & 78,46 \\
5. & 46,38 & 9,00 & 22,76 & 4,71 & 82,85 \\
6. & 20,85 & 7,13 & 16,37 & 4,00 & 48,35 \\
7. & 52,46 & 9,75 & 24,25 & 4,81 & 91,27 \\
8. & 58,20 & 9,76 & 24,90 & 4,85 & 97,71 \\
9. & 59,77 & 10,40 & 24,44 & 3,72 & 98,33 \\
10. & 60,00 & 10,00 & 24,25 & 4,49 & 98,74 \\
11. & 40,76 & 8,83 & 22,10 & 4,40 & 76,09 \\
12. & 27,90 & 7,90 & 15,01 & 3,67 & 54,48 \\
13. & 22,87 & 5,79 & 10,42 & 1,69 & 40,77 \\
14. & 49,87 & 9,29 & 19,63 & 4,62 & 83,41 \\
15. & 58,30 & 9,39 & 24,75 & 4,67 & 97,11 \\
\hline
\end{tabular}

Tabel 6: Hasil penilaian kualitas kulit dari DKI Jakarta Secara kuantitatip oleh Team BBKKP

\begin{tabular}{|c|c|c|c|c|c|}
\hline No & $\begin{array}{c}\text { Krupon } \\
(60)\end{array}$ & $\begin{array}{c}\text { Leher } \\
(10)\end{array}$ & $\begin{array}{c}\text { Perut } \\
(25)\end{array}$ & $\begin{array}{c}\text { Kaki+Ekor } \\
(5)\end{array}$ & $\begin{array}{c}\text { Jumlah } \\
\text { Nilai }\end{array}$ \\
\hline 1. & 60,00 & 10.00 & 25,00 & 4,76 & 99,76 \\
2. & 56,33 & 9,87 & 21,64 & 4,94 & 92,76 \\
3. & 60,00 & 9,55 & 25,00 & 5,00 & 99,55 \\
4. & 45,37 & 10,00 & 25,00 & 4,88 & 85,25 \\
5. & 57,78 & 9,84 & 19,15 & 4,94 & 91,71 \\
6. & 43,50 & 9,84 & 24,60 & 4,94 & 82,88 \\
7. & 44,62 & 9,54 & 24,59 & 4,82 & 83,57 \\
8. & 47,77 & 9,50 & 24,22 & 4,47 & 85,96 \\
9. & 50,25 & 8,37 & 20,94 & 4,84 & 84,40 \\
10. & 58,68 & 9,84 & 24,22 & 4,94 & 97,68 \\
11. & 52,38 & 9,31 & 24,68 & 4,94 & 91,31 \\
12. & 29,43 & 9,03 & 23,05 & 4,89 & 66,40 \\
13. & 14,81 & 2,75 & 6,12 & 1,37 & 25,05 \\
14. & 14,25 & 2,38 & 5,94 & 1,18 & 23,75 \\
15. & 16,27 & 2,75 & 1,37 & 1,37 & 27,03 \\
\hline
\end{tabular}

Tabel 7 : Hasil Penilaian Kulit secara kualitatip di Jawa Timur dan Jawa Tengah

\begin{tabular}{|c|c|c|c|c|}
\hline & \multicolumn{2}{|c|}{ Jawa Timur } & \multicolumn{2}{c|}{ Jawa Tengah } \\
\cline { 2 - 5 } & $\begin{array}{c}\text { Penilaian Peda- } \\
\text { gang/penyamak }\end{array}$ & $\begin{array}{c}\text { Penilaian } \\
\text { Team BBKKP }\end{array}$ & $\begin{array}{c}\text { Penilaian peda- } \\
\text { gang/penyamak }\end{array}$ & $\begin{array}{c}\text { Penilaian } \\
\text { Team BBKKP }\end{array}$ \\
\hline 1. & II & II & I & II \\
2. & I & I & III & AF \\
3. & III & AF & III & III \\
4. & I & I & V & AF \\
5. & I & II & III & III \\
6. & I & I & III & AF \\
7. & II & II & II & AF \\
8. & I & I & III & AF \\
9. & IV & AF & III & AF \\
10. & I & I & III & AF \\
11. & I & I & II & III \\
12. & I & II & II & III \\
13. & IV & AF & II & III \\
14. & II & III & I & III \\
15. & II & III & II & III \\
16. & IV & AF & IV & AF \\
17. & III & AF & II & III \\
18. & IV & AF & IV & AF \\
19. & II & III & II & III \\
20. & IV & III & I & III \\
\hline
\end{tabular}


Tabel 8: Hasil Penilaian kulit secara kualitatip di Jawa Barat dan DKI Jakarta

\begin{tabular}{|c|r|r|r|r|}
\hline & \multicolumn{2}{|c|}{ Jawa Barat } & \multicolumn{2}{|c|}{ DKI Jakarta } \\
\cline { 2 - 5 } & $\begin{array}{c}\text { Penilaian Peda- } \\
\text { gang/penyamak }\end{array}$ & $\begin{array}{c}\text { Penilaian } \\
\text { Team BBKKP }\end{array}$ & $\begin{array}{c}\text { Penilaian peda- } \\
\text { gang/penyamak }\end{array}$ & $\begin{array}{c}\text { Penilaian } \\
\text { Team BBKKP }\end{array}$ \\
\hline 1. & I & I & I & I \\
2. & III & AF & I & I \\
3. & I & I & I & I \\
4. & III & III & I & II \\
5. & II & II & I & I \\
6. & IV & AF & II & II \\
7. & I & I & II & II \\
8. & I & I & I & II \\
9. & I & I & I & II \\
10. & I & I & I & I \\
11. & II & III & I & I \\
12. & II & AF & III & II \\
13. & V & AF & AF & AF \\
14. & II & II & AF & AF \\
5. & I & I & AF & AF \\
\hline
\end{tabular}

Dari tabel 3 sampai dengan tabel 8 , menurut penilaian team BBKKP dat dihitung rata-rata nilai kuantitatip kulit kambing mentah yang diawet dean sinar matahari diseluruh Pulau Jawa adalah sebagai berikut :

talitas I: $\begin{array}{llr}\Sigma X & = & 1891,21 \\ \mathrm{n} & = & 19 \\ \mathrm{X} & = & 95,74 \\ \mathrm{SD} & = & \pm 5,26\end{array}$

ri tabel 1 dapat dilihat bahwa nilai kualitas kulit $=95,74$ tersebut berada am katagori sempurna.

alitas II :

$$
\begin{array}{llr}
\Sigma X & = & 1011,55 \\
\mathrm{n} & =12 \\
\mathrm{X} & = & 84,74 \\
\mathrm{SD} & = & \pm 2,82
\end{array}
$$

ri tabel 1 dapat dilihat bahwa kualitas kulit $=84,29$ tersebut berada dakatagori sempurna.

alitas III : $\begin{array}{rrr}\Sigma \mathrm{X} & = & 1169,01 \\ \mathrm{n} & = & 17 \\ \mathrm{X} & = & 68,76 \\ \mathrm{SD} & = & \pm 5,57\end{array}$

Dari tebel 1 dapat dilihat bahwa nilai kuantitatip kulit $=68,76$ tersebutberdalam kategori baik.

$\begin{array}{rlc}\text { Kualitas IV }: \Sigma \mathrm{X} & = & 900,29 \\ \mathrm{n} & = & 2 \\ \mathrm{X} & = & 40,92 \\ \text { SD } & = & \pm 11,88\end{array}$

Dari tabel 1 dapat dilihat bahwa nilai kuantitatip kulit $=40,92$ tersebut berada dalam kategori jelek.

Dari tabel 7 dan tabel 8 dihitung prosentase hasil penilaian kulit secara kualitatip oleh pedagang/pengumpul (P) dengan team BBKKP (B). Seperti tabel berikut :

Tabel 9: Prosentase hasil penilaian kulit secara kualitatip oleh peadagang/penyamak $(\mathrm{P})$ dan, team BBKKP (B)

\begin{tabular}{|l|l|c|c|c|c|c|c|c|c|c|c|}
\hline \multirow{2}{*}{ No } & \multirow{3}{*}{ Lokasi } & \multicolumn{4}{|c|}{ A (\%) } & \multicolumn{5}{|c|}{ B (\%) } \\
\cline { 3 - 12 } & & I & II & III & IV & AF & I & II & III & IV & AF \\
\hline 1. & Jawa Timur & 40 & 25 & 15 & 20 & - & 30 & 20 & 20 & - & 30 \\
2. & Jawa Tengah & 15 & 35 & 35 & 15 & - & 0 & 5 & 50 & - & 45 \\
3. & Jawa Barat & 47 & 27 & 13 & 13 & - & 47 & 13 & 13 & - & 27 \\
4. & DKI Jakarta & 53 & 20 & 7 & - & 20 & 40 & 33 & 7 & - & 20 \\
\hline
\end{tabular}

\section{PEMBAHASAN}

Cara penilaian kulit yang dilakukan oleh para pedagang/pengumpul kulit serta para pengusaha penyamakan kulit di Pulau Jawa (Jawa Timur, Jawa Tengah, Jawa Barat, dan DKI Jakarta) pada umumnya telah berpedoman seperti yang dikatakan oleh Aten et al (1955) dan BPK (1962).

Dalam menentukan kualifikasi kualitas kulit mentah berdasarkan kriteria cacat-cacat yang terdapat pada kulit, pada umumnya juga telah berpedoman pada pendapat Aten et al (1955) dan BPK (1962)

Hasil penilaian kualitas kulit secara kuantitatip dengan menggunakan tabel 2, tabel penilaian kualitas kulit, didapatkan nilai rata-rata yaitu : kuali$\operatorname{tas} I=95,74$; kualitas II $=84,29$; kualitas III $=68,76$; dan kualitas IV $=40$, 92.

Hasil klasifikasi kulit secara kualitatip menurut para pedagang/pengumpul kulit serta para pengusaha penyamak kulit dengan team BBKKP, terdapat perbedaan prosentase hasil $25 \%$ ( untuk kualitas I dan II ), sedang untuk kualitas III dan IV/afkir, prosentase naik sebesar $+25 \%$. Penurunan kualitas-kualitas tersebut disebabkan adanya faktor selama penyimpanan dan transport yang tidak memenuhi syarat, hal ini sesuai dengan pendapat Suermondt (1948) serta adanya faktor subyektip dari penilai kulit.

VOL VIII No. 14 Tahun 1992/1993 


\section{KESIMPULAN}

1. Penilaian kulit mentah kambing yang diawet dengan sinar matahari secara organoleptis berdasarkan cacat-cacat yang ada pada kulit tidak dapat dipergunakan sebagai dasar penyusunan konsep standar mutu kulit mentah, karena sangat dipengaruhi oleh faktor subyektivitas.

2. Tabel penilaian kualitas kulit (tabel 2) yang disesuaikan oleh team BBKKP dapat dijadikan pedoman untuk dasar penilaian kualitas kulit mentah kering yang diawet dengan sinar matahari secara kuantitatip.

3. Penilain kualitas kulit mentah kambing yang diawet dengan sinar matahari secara organoleptis berdasarkan kriteria cacat-cacat yang ada pada kulit menurut B.P.K. (1962) dapat dijadikan pedoman dalam grading kulit mentah.

\section{DA F T A R PUSTAKA}

1. ATEN A,A. INNES DAN E. KNEW, 1960, " Flaying and Curing of hides and Skins as a Rural Industry ", F.A. O.

2. BALAI PENELITIAN KULIT , 1972, "Kaleidoskop dari kulit Hewan Mentah sampai Barang Jadi" BPK Yogyakarta.

3. HERNOWO H. S. 1972, "Penentuan Kwalitas kulit kambing mentah di Jawa Timur Skripsi Fakultas Peternakan Universitas Gadjah Mada.

4. WIKANTADI, B. DKK. 1977, "Peningkatan Ketrampilan Pengkulit" Laporan Penelitihan team 11/BPK/1977-1978 Balai Penelitian Kulit Yogyakarta.

5. SUERMONDT JOH. R. 1978, "Tecnologie der Lederbereideng" Boek A: N.V Zuid, Nederlansche Dreekkerrij; S. Hertogenbosch.

6. JUDOADMIDJOJO, M. R. 1981, " Defek-defek pada kulit mentah dan kulit samak", Departemen Teknologi Hasil Pertanian Institut Pertanian Bogor. 